\title{
Curbing rampant cross-contamination and misidentification of cell lines
}

\author{
Roland M. Nardone \\ Department of Biology, Catholic University of America, Washington, DC, e-mail: nardone@cua.edu
}

A son's challenge started an emeritus professor of biology on a three-year odyssey to get biological researchers to correct a decades-long problem with cross-contaminated and misidentified cell lines. These errors may account for more than $15 \%$ of mammalian cultures, wasting resources and undermining the integrity of research.

\section{Introduction}

In 2005, on my birthday, my son threw down a challenge that sent me on a three-year odyssey that has revealed some of the best and too much of the worst about the profession of biology: "Happy birthday, Dad," he greeted me as I came into the offices we share at Foundation for Advanced Education in the Sciences (FAES) at the National Institutes of Health (NIH). "What are you going to do with the rest of your life?"

What, indeed? It would have to be worthwhile, a fitting last act to a productive career. And yet it would have to be something that one person could complete, without much cost and bureaucratic entanglement. Something that could be done quickly.

Fortunately, a proper objective for this quest (or the theme of the swan song, if you prefer) was close at hand: it was time to attack the widespread cross-contamination and misidentification of cell lines used for biomedical research. Every year, I deliver a lecture on cell line cross-contamination to the attendees of the Cell Culture Training Course we run for FAES. The lecture is a litany of cases of interspecies and intraspecies cross-contamination, an anthology of sad tales of invalidated research and squandered millions. On the brighter side, I also chart the causes and teach possible preventive and corrective measures. Class attendees learn that awareness of this widespread problem dates back to S.M. Gartler's work in 1966 and 1967 (1). And they learn that today, forty years later, researchers continue to publish data derived from cross-contaminated and misidentified cell lines.

Gartler, for example, showed that the cell lines labeled KB, Hep-2, Chang liver, Int-407, and WISH were not, in fact, from the tissues they purported to represent (1). They were, rather, HeLa, a human cervical adenocarcinoma cell line. And yet a Medline search of the literature for the years 2000-2004 uncovered 19 citations for Int-407, 55 for WISH, 59 for Chang liver, 476 for Hep-2, and 556 for KB (2). In 1981, Nelson-Rees et al. (3) reported that a putative mongoose line was actually derived from humans, that one putative hamster cell line was actually marmosetderived while another was human, that six supposedly independent human cell lines procured from Russian scientists were all HeLa (4) and that the $Y$ chromosomes of many cell lines were not where they were supposed to be. It has been conservatively estimated that more than $15 \%$ of cell culture studies are based on misidentified or crosscontaminated cell lines. When I see examples like this, I cannot help asking myself, "Have the Marx Brothers taken over the cell culture labs?"

Earlier attempts to rectify this problem failed. The scientific community was not properly or thoroughly mobilized. No one presented plans for ensuring cell line authentication. These problems, I thought, could be remedied, and recent technology developments would make the task easier, more reliable, and less expensive. By the time I headed for home on that birthday, I had a cause.

\section{Denial}

Nelson-Rees was ideally positioned to expand Gartler's findings. As curator for a National Cancer Institute cell repository in Oakland, CA, he received a large number of cell lines from laboratories throughout the world and had each cell line thoroughly characterized before it was frozen. His reports of extensive interspecies and intraspecies crosscontamination and misidentification constitute a major tour de force involving good collaborations that permitted the application of diverse methods (5-7).

Some researchers caught in the unwanted glare of Nelson-Rees's spotlight were prominent figures noted for running tight ships. Their public responses were heavily laced with denial and mockery (8). The cumulative impact of hundreds of cases of unsuspected mischaracterized cell lines - and the near absence of credible rebuttals - gradually quelled the controversy.

In 1978, the American Type Culture Collection reported that it had housed and unwittingly distributed misidentified cultures, primarily lines from ATCC's oldest accessions, obtained prior to the introduction of cell line characterization methods (9). Though this revelation validated the warnings of Gartler and Nelson-Rees (if validation was necessary), professional interest in the issue waned. Leaders who 


\section{Tech Insight}

might have persuaded professional societies, scientific journals, and underwriters of research did not take up the challenge.

As a result, cell culture users have adopted a rigorous quality-control regimen (testing sterility; precisely controlling temperature, $\mathrm{pH}$, osmotic pressure, and chemical purity; recording lot numbers; storing properly; defining nutrient media; eliminating endotoxins; and many similar measures), but they seldom confirm the authenticity of the protagonist of the research drama-the cell line. A 2004 survey of 483 respondents by Buehring et al. (10) showed that only $33 \%$ tested for authenticity.

\section{Those Who Ignore History . . .}

Devising an effective authentication strategy requires us to understand the factors that produced the current problem. Misidentification and cross-contamination presumably occurred for decades before Gartler's report in 1966. The errors likely escaped detection because researchers assumed that many changes in cell cultures resulted from the in vitro environment and a change in gene expression, rather than from mislabeling or the unwitting introduction of an alien cell. Gartler showed that 18 cell lines, supposedly of independent origin, possessed the Type $A$ isoenzyme of glucose-6-phosphate dehydrogenase (1). Type A G-6-PD is found only in people of African descent (at a frequency of $30 \%$ ) and is not found in Caucasians. All 18 cell lines proved to be descendent HeLa cells (derived, of course, from Henrietta Lacks, a Maryland woman who died in 1951).

HeLa, isolated by Gey (11), was the first human cancer cell line to be established in culture. It was widely distributed, passing from investigator to investigator, throughout the world. HeLa's frequent appearance as a contaminant $(7,10)$ supports the view that many recipients were either careless in their lab technique or succumbed to the inevitability of human error.

A number of factors contributed greatly to cross-contamination and misidentification.

- Cells in culture are pleiomorphic, assuming in their artificial environment a variety of morphologies that are usually very different from their appearance and behavior in situ. Many factors influence these morphological variations: population density, media composition, and the substratum for attachment, for example.

- With the notable exceptions of karyotyping [which requires a relatively uncommon expertise (12)] and isoenzyme profiling (13), earlier researchers lacked practical and distinctive morphological and biochemical markers for distinguishing one species or cell line from another.

- The collective failure to maintain and use cell banks required investigators to repeatedly subculture their cell lines.

- Lateral transfer of nonauthenticated cell lines from one investigator to another, instead of using a major repository as a source, increased the probabilities of contamination and error.

- The rapid adoption of cell culture technology for extremely diverse biomedical investigationswithout rigorous formal training-also increased errors.

One would expect that the same rigorous techniques that prevented widespread bacterial contamination would have prevented the spread of cross-contaminated cell lines. The history of mycoplasma contamination provides a lesson. Mycoplasma are among the smallest bacteria and are capable of passing through cotton plugs of pipets and filters with a pore size of 0.2 microns. They have atypical growth requirements and, because of their extremely small size, do not cause turbidity of contaminated cultures. Isolating them requires special media, anaerobic conditions, microscopic examination of agar plates, and four weeks of waiting (14). Mycoplasma contamination arising from porcine trypsin, bovine serum, or mouth pipeting was commonplace and has persisted in cell cultures for decades. Investigators sounded alarms as they realized the many detrimental effects of mycoplasma contamination, such as alteration of nucleic acid synthesis pathways, chromosome breakage, arginine depletion, and interference with cell fusion. The U.S. Food and Drug Administration prohibited the use of untested cultures for research or manufacture of products under its control. Leadership provided by the Society for In Vitro Biology (formerly the Tissue Culture Association) and by serum collection companies was significant but it did not lead to universal compliance despite test improvement. Mycoplasma contamination continued to interfere with or invalidate too much research (15) despite the appearance of faster, easier, and more sensitive detection methods.

PCR methods enabling the detection of low levels of contamination by virtually all species of mycoplasma are becoming the standard. Yet mycoplasma-contaminated cultures persist at a high incidence and continue to be used by those unwary, or indifferent, researchers. Despite occasional symposia and publications dealing with the consequences of mycoplasma contamination, the profession has failed to generate an all-embracing strategy that would reach all cell culture workers and ensure compliance. The reasons appear to be analogous to or the same as those responsible for the perpetuation of cross-contamination: lack of testing, the high long-term probability of human error, denial ("Not a problem in my lab."), and rapid adoption by workers unfamiliar with the pitfalls of cell culture and ill-grounded on technique.

As we will see later, in the context of cell line authentica- 
tion, there is a foolproof remedy. All it requires is a conscience courage, and when needed, a dose of outrage.

\section{Eradication}

To rally profession-wide support for a widespread policy of contamination control, I circulated a white paper, "Eradication of cross-contaminated cell lines: a call for action" (16). The paper was intended to be an up-to-date summary of the history of the issue from 1966 through 2005. It included encouraging responses from five scientific societies and four cell culture repositories.

Most importantly, it outlined the route to a solution:

- Professional societies have an obligation to play an important role in the education of their members and others, and also serve as the conscience and guardian of scientific integrity. Hence, they should get heavily involved in the cross-contamination issue.

- Universal compliance can be achieved if organizations that dispense grant funds and journals that publish research outcomes would adopt a zero tolerance policy with respect to the award of grants and acceptance of manuscripts to be published. No cell line authentication, no grant; no cell line authentication, no access to journals as publication outlets.

In retrospect, I did not expect that a very hard sell would be necessary to elicit more than token verbal support. The large number of publications based on misidentified or cross-contaminated cell lines was clear testimony that the cell culture community needed to make significant progress. A zero tolerance policy would, relatively, neither intrude nor drain resources. Such a policy would also harmonize with the missions of granting agencies, journals, and professional societies-all of them run by intelligent, dedicated, hard-working people.

As things turned out, it appeared that policymakers of the private sector were so sharply focused on their overload of traditional responsibilities that they chose not to dwell on the issue. The slow response and ambiguous responses from the scientific "grassroots" suggested that a change of tactic was needed. It would be better to concentrate on getting the backing of a special, powerful, and respected organization with broad influence throughout biomedical research.

The Office of Extramural Research (OER) of the NIH appeared to be ideally positioned to provide the leadership. Its grants program, directly or indirectly, reaches virtually all biomedical researchers in the United States and abroad. The OER has a responsibility to the public trust to ensure that grant money is spent as wisely as possible, and therefore its grant application and review system would make a natural vehicle for confirming cell line authentication.
Though the NIH decided it could not take a lead role in requiring proof that cultures are what they purport to be, $\mathrm{NIH}$ has become a strong ally, thanks to the conscience and courage of their director, Elias Zerhouni, and deputy directors, Norka Ruiz Bravo and Michael Gottesman.

\section{Increasing Momentum}

Several factors helped move the cell authentication initiative forward. John Masters of University College London and Joseph Perrone, then vice president for Standards at ATCC, volunteered their services three years ago. Despite their heavy schedules, they continue to serve as sources of information and wisdom.

At an autumn 2005 meeting in his office, Lawrence Rhoades, a sociologist in the HHS Office of Research Integrity, explained to me that ORI addresses fraud and plagiarism, but not blatantly poor science. Though I left his office somewhat discouraged, I arrived at my own desk an hour later to learn that Rhoades was sending out 45,000 e-mail messages to the research community, calling attention to the white paper.

Writers for Science received that message. So did James Paul, a senior staff member of the Congressional Committee on Science. Science followed up with a news article on cross-contamination and misidentification (17). BBC Radio picked up the Science report (as part of a longer investigation of waste in UK cancer research). Both the U.S. National Cancer Institute and Cancer Research UK maintain authenticated cell line collections for researchers. The National Cancer Institute ( $\mathrm{NCl}$ ) has 60 cancer cell lines available for drug testing and other research. In 2007, Liscovitch and Ravid reported that one of these cultures was not a model breast cancer cell line, as listed, but an ovarian cancer cell (18). The authors indicated that about 300 research papers based on that misidentified cell line are now part of the literature.

Although dialogue continued and even expanded with Ruiz Bravo and Walter Schaffer (a senior scientist of the Office of the Director), concrete action was slow in coming. We decided to convene an expert panel of about 20 scientists to review the white paper and its proposals. It was agreed that if approval was given, an Open Letter from the panel of concerned scientists would be sent to Michael Leavitt, Secretary of the U.S. Department of Health and Human Services (HHS). The letter would emphasize that the Extramural Research Program at the NIH should be encouraged to address the issue.

The expert panel did agree, and we sent the Open Letter on July 11, 2007, Secretary Leavitt responded quickly, and asked the director of the NIH, Elias Zerhouni, to look into the matter. And on November 28, 2007, Deputy Directors Ruiz Bravo and Gottesman published an addition to the NIH Guidelines for Research ("Notice regarding authenti- 
cation of cultured cell lines"; NOT-OD-08-019). The notice encourages (but does not require) cell line authentication by researchers in both the intramural and extramural programs. And it urged (but did not require) grantors and publishers to increase their oversight. It was a big step forward, but well short of zero tolerance.

Dr. Schaffer explained to me that mandating testing-and specifying particular tests-would conflict with the spirit of the grants program, which encourages individual responsibility for the conduct and direction of sponsored research. And, in fact, though our 20-member expert panel thought that authentication should be mandatory for cell lines used for sponsored research, it did not indicate how the lines should be authenticated. Those particulars would be left to principal investigators and peer reviewers. (It should be noted that short tandem repeat (STR) DNA profiling, such as is used for forensics, is inexpensive and has been very effective for authenticating human cell lines [19].)

\section{Progress}

What action would be appropriate in light of the experience of the last three years? By most measures, significant progress has been made. One journal (Cell Biochemistry and Biophysics) now requires authors to authenticate. A second one (BioTechniques) now asks authors to comment on the authenticity of their cell lines. It appears that the board of the Council of Science Editors will soon address cell line contamination at a board meeting. Although a number of granting organizations (other than the $\mathrm{NIH}$ ) have been following the initiative, we have deferred efforts to mobilize them while we confer with the $\mathrm{NIH}$.

Professional societies are cohesive entities that can and should play an important role in educating the membership with regard to the existing problem and its solution. Through workshops and other training activities members could learn how to use various approaches to authentication.

Two special needs must be addressed in the future. We need a data bank listing all cell lines reported to be crosscontaminated or misidentified. And we need a library of animal-cell DNA profiles comparable to those now in use for human cell lines. This would then allow for distinctions to be made among cell lines derived from different individuals of the same strain.

Two concluding points of emphasis follow. Compliance with an authentication standard has no chance of success without appropriate, unambiguous rewards and deterrents. The zero tolerance policy provides the opportunity for success. Second, is there any quality/integrity issue confronting the science community more compelling than the issue of rampant cross-contamination and misidentification of cell lines used for biomedical research? I don't think so.

\section{REFERENCES}

1. Gartler, S.M. 1967. Genetic markers as tracers in cell culture. $\mathrm{NCl}$ Monograph 26: Second Decennial Review Conference on Cell, Tissue and Organ Culture. NCI, Bethesda, MD, p.167195.

2. Masters, J.R. 2005. DNA profiling and the authentication of cell lines. In Vitro Cell. Dev. Biol. 41:6A.

3. Nelson-Rees, W.A., D.W. Daniels, and R.R. Flandermeyer. 1981. Cross-contamination of cells in culture. Science 212:446-452.

4. Gold, M. 1985. Conspiracy of Cells. State University of New York Press. Albany, NY. 170 pp.

5. O'Brien, S.J. 2001. Cell culture forensics. Proc. Natl. Acad. Sci. USA 98:7656-7658.

6. Nelson-Rees, W.A., R. Flandermeyer, and P. Hawthorne. 1974. Branded marker chromosomes as indicators of intraspecies cellular contamination. Science 184:1093-1096.

7. Nelson-Rees, W.A. and R.R. Flandermeyer. 1977. Inter- and intra-species contamination of human breast tumor cell lines $\mathrm{HBC}$ and $\mathrm{Br} \mathrm{Ca} 5$ and other cell cultures. Science 195:13431344.

8. Shapley, D. 1974. HeLa cell contaminating cultures around the world. Science 184:1059-1061.

9. Lavappa, K.S. 1978. Survey of ATCC stocks of human cell lines for HeLa contamination. In Vitro 14:469-475.

10. Buehring, G.C., E.A. Eby, and M.J. Eby. 2004. Cell line crosscontamination: how aware are mammalian cell culturists of the problem and how to monitor it? In Vitro Cell. Dev. Biol. Anim. 40:211-215.

11. Gey, G. 1955. Some aspects of the constitution and behavior of normal and malignant cells maintained in continuous culture. Harvey Lect. 1954-1955 50:154-229.

12. O'Brien, S.U., G. Kleiner, R. Olson, and J.E. Shannon. 1977. Enzyme polymorphisms as signatures in human cell cultures. Science 195:1345-1348.

13. Freshney, R.I. 1994. Culture of Animal Cells, 3rd ed. WileyLiss, New York.

14. Freshney, R.I. 2008. Authentication of cell lines: ignore at your peril. Expert Rev. Anticancer Ther. 8:311-314.

15. Ryan, J. 2008. Understanding and Managing Cell Culture Contamination. Corning Technical Bulletin. Corning, NY.

16. Nardone, R.M. 2007. Eradication of cross-contaminated cell lines: a call for action. Cell Biol. Toxicol. 23:367-372.

17. Chatterjee, R. 2007. Cases of mistaken identity. Science 315:928-931.

18. Liscovitch, M. and D. Ravid. 2007. A case study in misidentification of cancer cell lines: MCF-7/AdrR cells (re-designated $\mathrm{NCl} / \mathrm{ADR}-\mathrm{RES}$ ) are derived from OVCAR- 8 human ovarian carcinoma cells. Cancer Lett. 245:350-352.

19. Masters, J.R., J.A. Thomson, B. Daly-Burns, Y.A. Reid, W.G. Dirks, P. Packer, L.H. Toji, T. Ohno, et al. 2001. Short tandem repeat profiling provides an international reference standard for human cell lines. Proc. Natl. Acad. Sci. USA 98:80128017. 